\title{
TYPE B TYMPANOGRAM PATTERNS CAN PREDICT AIR-BONE GAP VALUE IN OTITIS MEDIA WITH EFFUSION
}

\author{
Marev D. \\ Department of Otorhinolaryngology, St. Marina University Hospital of Varna, \\ Medical University of Varna
}

\begin{abstract}
Tympanometry is well-established means of assessing the presence of fluid in the middle ear. Type B tympanogram is, usually, considered a unique entity. However, its shape may vary from a rounded type $B$ with a 'pseudopeak' to a completely flat response. The aim of this study was to compare type B tympanogram curve (maximum admittance, tympanometric peak pressure, and area under the curve) with the viscosity of the middle ear fluid and with the air-bone gap (ABG). A total of 93 ears of 67 children were examined. The children underwent ventilation tube insertion. No correlation was found between the viscosity of the middle ear fluid and B tympanogram curve values. However, these values varied between a low ABG (0 to $20 \mathrm{~dB})$ and a high ABG $(>20 \mathrm{~dB})$. A statistical difference was established for the three parameters (maximum admittance, $\mathbf{p}<0,0025$; pressure, $\mathbf{p}<0,025$, and area under the curve, $\mathbf{p}<0,0005$ ). Ti was concluded that tympanometry may be used as an objective measure to estimate the extent of conductive hearing loss, especially in infants and young children.
\end{abstract}

Key words: air-bone gap, conductive hearing loss, otitis media with effusion, tympanometry, audiometry

\section{INTRODUCTION}

Tympanometry values change in the acoustic admittance of the ear as a function of the pressure in the sealed external ear canal. Since Liden (11) and Jerger (9) published their classification system, tympanometry has become widely accepted. tympanograms were classified as types A, B, and $C$ (9). Types A and C are characterized by the presence of a peak close to 0 decapascals $(\mathrm{daPa})$ in type $\mathrm{A}$, and negative (equal to or less than -100 daPa) in type C. In the type B tympanogram, there is no distinct peak and the admittance does not significantly change during pressure variations in the external auditory canal. A type B tympanogram may be either straight, or with a pseudopeak ('rounded B'). In clinical practice, it is generally related to fluid in the middle ear $(3,4)$. The curve of a tympanogram may be further defined by 3 major characteristics: i) the maximum acoustic admittance of the ear, which is the value of the admittance at the peak of the tympanogram and the pressure at the peak of the tympanogram which reflects the pressure in the middle ear as well as the gradient which represents the flatness of the curve. Three methods of gradient calculation have been described $(1,4,5,13)$. The acoustic admittance describes the ease with which sound energy flows through a system (2). Admittance may be expressed either by acoustic mho (ohm

Address for correspondence:

D. Marev, Dept. of Otorhinolaryngology,

St. Marina University Hospital of Varna,

55 Marin Drinov Str., Varna 9002, Bulgaria

e-mail:dmarev@abv.bg spelled backwards), or by an equivalent volume of air (cubic centimeters). The normal static admittance of the middle ear varies between 0,3 and 1,6 mmho $(8,10)$.

Most studies attempting to find a correlation between values of maximum admittance or gradient and the status of the middle ear have dealt with type A tympanograms. Studies of type B tympanogram patterns are scanty. The difficulty is that whereas in a 'round B' curve with a pseudopeak, the three aforementioned parameters can be measured, while in a straight curve, a gradient (whatever the mode of calculation) is not measurable. Thus, a comparison between different $\mathrm{B}$ curves is difficult to make.

\section{MATERIAL AND METHODS}

The study covered 67 children scheduled for ventilation tube insertion. All of them underwent tympanometry and audiometry, including speech recognition threshold. Pure tone thresholds to air and to bone stimuli were performed when possible, according to the age of the children. On the next day, ventilation tubes were inserted under general anesthesia. Middle ear fluid, when found in sufficient quantity, was sampled for viscosity measurement. Children from whom neither the $A B G$, nor viscosity measures were obtained were not included in the study.

Single-probe frequency tympanometry $(226 \mathrm{~Hz})$ was performed by means of an Amplaid 720. The test was done in the 'compensated' mode. This mode enables recording of tympanograms compensated for the effect of the ear canal; i. e., the flat portion of the tympanogram (the ear canal por- 
tion) is arithmetically subtracted from the tympanogram peak. This tympanogram can be referred to as a measure taken at the lateral surface of the tympanic membrane. Audiometry was performed in a sound-proof chamber with an intra-acoustic AC40 audiometer. An average ABG value was calculated (summation of $A B G$ value at 500 , 1000 , and $2000 \mathrm{~Hz}$ in decibels, divided by 3 ). The ABG results were also separated into 2 groups: a low $\mathrm{ABG}$ (0 to 20 $\mathrm{dB})$ and a high $\mathrm{ABG}(>20 \mathrm{~dB})$.

After paracentesis, middle ear fluid was aspirated. It was centrifuged to separate red blood cells and then weighed and diluted by 20 times its weight with normal saline solution $(0,9 \%$ sodium chloride).

\section{RESULTS AND DISCUSSION}

Only a small number of studies have compared the characteristics of the type B tympanogram and the magnitude of hearing loss in children with middle ear effusion $(6,12)$. Studies that have compared the gradient with other parameters in the presence of a type B tympanogram with no peak gave values of $0 \mathrm{mmho}$ for $\mathrm{G}$ difference, 0 for $\mathrm{G}$ ratio, and $400 \mathrm{daPa}$ for $\mathrm{G}$ width (5). This is our reason for suggesting the use of the area under the curve as a new parameter for characterizing the type B tympanogram. This measure varies with the median value of the compliance. When expressed in square centimeters, it depends on the size of the printed graph. The median value of the compliance may also be calculated by dividing the area under the curve by the lengthwise measurement of the pressure.

No correlation was found between the viscosity of the middle ear fluid and the characteristics of the tympanogram. Other studies have tried to compare the magnitude of hearing loss and the viscosity of the fluid $(6,7)$.

$\mathrm{ABG}$ magnitude and thus tympanogram patterns seemed to be mostly related to the quantity of fluid present in the middle ear cleft. There was a positive correlation between the amount of hearing loss and the volume of fluid present in the middle ears of cats.

We did not measure the quantity of fluid during the surgical procedure for 2 reasons. First, tube insertion was performed under general anesthesia in the supine position, with ventilation administered by a mask. It was hard to compare the quantity of fluid aspirated under such conditions with the quantity of fluid present in the middle ear during audiometric measures on the previous day. Second, if the amount of fluid played a role for ABG magnitude, it was mainly the percentage of fullness of the middle ear that was significant, i. e., the amount of fluid relative to the volume of the middle ear cleft, rather than the amount of fluid itself.

\section{CONCLUSION}

We can draw the conclusion that the single-probe frequency tympanometric measure of a type B tympanogram can supply clinicians with both qualitative and quantitative information about $\mathrm{ABG}$ magnitude. In our opinion, this can be a useful tool for objective evaluation of hearing in infants and young children with middle ear effusion.

\section{REFERENCES}

1. Alper, C. M., W. J. Doyle. MRI validation of the accuracy of tympanometric gradient for the diagnosis of OME.- Br. J. Audiol., 33, 1999, No 4, 233-239.

2. Block, M. G., T. L. Wiley. Overview and basic principles of acoustic immitance.- In: Handbook of clinical audiology. J. Katz, ed. $4^{\text {th }}$ ed. Baltimore, Williams and Wilkins, 1994, 271-282.

3. Bluestone, C. D., Q. C. Beery, J. L. Paradise. Audiometry and tympanometry in relation to middle ear effusions in children.- Laryngoscope, $\mathbf{8 3}$, 1973, No 4, 594-604.

4. Brooks, D. N. An objective method of detecting fluid in the middle ear.- Int. Audiol., 7, 1968, 280-286.

5. de Jonge, R. Normal tympanometric gradient: a comparison of three methods.- Audiology, 25, 1986, No 4-5, 299-308.

6. Fiellau-Nikolajsen, M. Tympanometric prediction of the magnitude of hearing loss in preschool-children with secretory otitis media.- Scand. Audiol., 1983, Suppl. 17, 68-72.

7. Goodhill, V., A. L. Holcomb. The relation of auditory response to the viscosity of tympanic fluids.Acta Otolaryngol. (Stockholm), 49, 1958, No 1, 38-46.

8. Hall, J. W. Effects of age and sex on static compliance.- Arch. Otolaryngol., 105, 1979, No 3, 153-156.

9. Jerger, J. Clinical experience with impedance audiometry.- Arch. Otolaryngol., 92, 1970, No 4, 311-324.

10. Jerger, J., S. Jerger, L. Mauldin. Studies in impedance audiometry. I. Normal and sensorineural ears.- Arch. Otolaryngol., 96, 1972, No 6, 513-523.

11. Liden, G. Tests for stapes fixation.- Arch. Otolaryngol., 89, 1969, No 2, 399-403.

12. Margolis, R. H., L. L. Hunter, G. S. Giebink. Tympanometric evaluation of middle ear function in children with otitis media.- Ann. Otol. Rhinol. Laryngol., 1994, Suppl. 163, 34-38.

13. Paradise, J. L., C. G. Smith, C. D. Bluestone. Tympanometric detection of middle ear effusion in infants and young children.- Pediatrics, 58, 1976, No 2, 198-210. 